\title{
Enterohepatic bacterial infections dysregulate the FGF15-FGFR4 endocrine axis
}

\author{
Guillaume Romain ${ }^{1}$, Sarah Tremblay ${ }^{1}$, Ellen T Arena ${ }^{2,5}$, L Caetano M Antunes ${ }^{2,6}$, Scott Covey ${ }^{3}$, Michael T Chow ${ }^{4,7}$, \\ B Brett Finlay ${ }^{2,3}$ and Alfredo Menendez ${ }^{*}$
}

\begin{abstract}
Background: Enterohepatic bacterial infections have the potential to affect multiple physiological processes of the body. Fibroblast growth factor 15/19 (FGF15 in mice, FGF19 in humans) is a hormone that functions as a central regulator of glucose, lipid and bile acid metabolism. FGF15/19 is produced in the intestine and exert its actions on the liver by signaling through the FGFR4- $\beta$ Klotho receptor complex. Here, we examined the in vivo effects of enterohepatic bacterial infection over the FGF15 endocrine axis.

Results: Infection triggered significant reductions in the intestinal expression of Fgf15 and its hepatic receptor components (Fgfr 4 and Klb (BKlotho)). Infection also resulted in alterations of the expression pattern of genes involved in hepatobiliary function, marked reduction in gallbladder bile volumes and accumulation of hepatic cholesterol and triglycerides. The decrease in ileal Fgf15 expression was associated with liver bacterial colonization and hepatobiliary pathophysiology rather than with direct intestinal bacterial pathogenesis.

Conclusions: Bacterial pathogens of the enterohepatic system can disturb the homeostasis of the FGF15/19-FGFR4 endocrine axis. These results open up a possible link between FGF15/19-FGFR4 disruptions and the metabolic and nutritional disorders observed in infectious diseases.
\end{abstract}

Keywords: Endocrine, Metabolism, Enterohepatic, Infection, FGF15, FGF19, FGFR4, BKlotho, Salmonella, Listeria

\section{Background}

Alteration of the host's metabolism is common in infectious diseases; it can lead to patient malnutrition and the need for nutritional support $[1,2]$. Infection-driven metabolic changes are characterized by an accelerated flux of glucose, lipids, proteins and amino acids that may result in net protein loss and diabetic-like hyperglycemia $[1,2]$. Significant metabolic disorders have been observed in natural and experimental infections with the bacterium Salmonella enterica, including changes of the lipid and protein profiles and widespread hormonal imbalances $[1,3,4]$. In humans, Salmonella enterica serovar Typhi causes typhoid fever, a disease characterized by multiorgan bacterial colonization with common immunopathological manifestations in the gastrointestinal tract and the hepatobiliary system [5].

\footnotetext{
* Correspondence: alfredo.menendez@usherbrooke.ca

'Department of Microbiology and Infectious Diseases, Faculty of Medicine and Health Sciences, University of Sherbrooke, Cancer Research Pavilion, Rm Z8-1072, 3201, rue Jean-Mignault, Sherbrooke, Québec J1E 4K8, Canada Full list of author information is available at the end of the article
}

The molecular and physiological bases of the metabolic disorders observed during infection are not fully understood. In this work, we examined the disruption of the enterohepatic fibroblast growth factor 15/19 (FGF15/19)fibroblast growth factor receptor 4 (FGFR4) endocrine axis during bacterial infections of the enterohepatic system. FGF15/19 (FGF15 in mice, FGF19 in humans) is an endocrine factor secreted by intestinal enterocytes [6]. FGF15/19 has a crucial role in the control of whole body glucose and lipid metabolism and energy expenditure $[7,8]$. It is also a key regulator of de novo synthesis of bile acids via the repression of cholesterol 7 alpha hydroxylase (CYP7A1) expression in hepatocytes [9]. In addition, FGF15 represses the apical $\mathrm{Na}^{+}$-dependent bile acid transporter (ASBT) expression in hepatic cholangiocytes [10] and facilitates gallbladder filling by promoting gallbladder muscle distension [11]. Through these functions, FGF15/19 closes an important negative feedback loop in the regulation of bile acid homeostasis. Signaling to hepatic target cells occurs through the interaction of FGF15/19 with the tyrosine kinase receptor fibroblast growth factor receptor

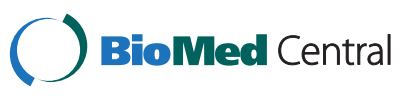


4 (FGFR4) and also requires the protein $\beta$ Klotho. Mice genetically deficient for Fgf15, Fgfr4 or Klb (BKlotho) have similar biliary phenotypes with higher levels of CYP7A1 and increased synthesis of bile acids [6,12-14]. Reduced FGF19 levels have been observed in patients with inflammatory bowel disease [15] and chronic idiopathic bile acid diarrhea [16]. On the other hand, patients with insulin resistance and non-alcoholic fatty liver disease, as well as extrahepatic cholestasis frequently display elevated plasma levels of FGF19 $[17,18]$.

Using a model of murine typhoid fever, we demonstrate that Salmonella enterica infection triggers major alterations in the hepatic biliary function gene expression program, promotes accumulation of hepatic cholesterol and triglycerides and leads to a significant reduction in physiological gallbladder bile volumes. In addition, Salmonella infection causes a substantial decrease in the expression of intestinal Fgf15, accompanied by a dramatic loss of hepatic FGFR4 and ßKlotho. These disturbances appear to be secondary to hepatic inflammation. Given the important role of the FGF15/19-FGFR4 endocrine axis as a central metabolic regulator, these alterations may be a major factor underlying the pathophysiology of bacterial infectious diseases.

\section{Methods}

\section{Bacterial strains and mouse infections}

Salmonella enterica serovar Typhimurium strains SL1344 $\left(\mathrm{Sm}^{\mathrm{r}}\right)$ and SB103 (invA) [19] and Listeria monocytogenes $10403 \mathrm{~s}\left(\mathrm{Sm}^{\mathrm{r}}\right)$ [20] were used in this study. Bacteria were grown overnight at $37^{\circ} \mathrm{C}$ in $\mathrm{LB}$ supplemented with $100 \mu \mathrm{g} / \mathrm{mL}$ streptomycin. Inoculum was prepared in sterile HEPES $100 \mathrm{mM}, \mathrm{NaCl} 0.9 \%, \mathrm{pH}$ 8.0. Animal protocols were approved by the Animal Care Committees of the University of British Columbia and the University of Sherbrooke. Eight weeks-old female C57BL/6 mice (The Jackson Laboratory, Bar Harbor, USA) were infected orally with $5 \times 10^{7}$ Salmonella SL1344, intravenously with $5 \times 10^{2}$ Salmonella SB103 or with Listeria $10403 \mathrm{~s}\left(2 \times 10^{9}\right.$ bacteria orally and $10^{4}$ intravenously). The animals were kept with food and water ad libitum through the duration of the study and were always sacrificed during the light period (10:00 $A M \pm 60$ minutes). The bile was collected by gallbladder resection and draining by puncture. For bacterial counts, tissues were homogenized using a Mixer Mill MM400 (Retsch $\mathrm{GmbH}$ ) followed by plating of serial dilutions in LB plates containing $100 \mu \mathrm{g} / \mathrm{mL}$ streptomycin. All infection experiments were done in duplicate using a total of 8-10 mice per group.

\section{Expression analyses}

Ileum and liver samples were collected for mRNA and protein analysis. The ileal samples were taken approximately $2 \mathrm{~cm}$ away from the ileo-cecal junction; liver samples were taken from the central lobule. RNA was extracted using the RNeasy kit (Qiagen) and cDNA was prepared using the Quantitech Reverse Transcription kit (Qiagen). Quantitative PCR (qPCR) were done on an Eppendorf RealPlex ${ }^{2}$ system using the DyNamo SYBR Green qPCR Kit (Thermo Scientific). All reactions were done in $10 \mu \mathrm{l}$ final volume with 40 cycles of 30 seconds denaturing at $95^{\circ} \mathrm{C}, 30$ seconds annealing at $60^{\circ} \mathrm{C}$ and 30 seconds extension at $72^{\circ} \mathrm{C}$ (except the annealing temperature for Ost $\beta: 62^{\circ} \mathrm{C}$ ). The relative expressions were calculated using the ddCt method and corrected for primer efficiencies according to Pfaffl et. al. [21]. The qPCR primers are listed in Table 1. Western blots were performed using total liver tissue lysates and antibodies against CYP7A1 (Abcam, ab65596, 1:1000), FGFR4 (Abcam, ab119378, 1:500), ßKlotho (R\&D, AF2619, 1:2000) and actin (SIGMA A4700, 1:1000).

\section{Microscopy}

For histological analysis, tissue sections were fixed in 10\% buffered formalin, embedded in paraffin and stained with H\&E. Alternatively, samples fixed in $3.5 \%$ paraformaldehyde and frozen-embedded in OCT were used for immunofluorescent microscopy as previously described [22]. Fluorescence was visualized using an Olympus IX81 microscope.

\section{Cholesterol and triglyceride determinations}

Cholesterol and triglycerides were assayed in liver lysates. A total of 40-100 mg of liver was homogenized with an ultra turrax (setting 5, 4 times for $15 \mathrm{sec}$ ) in $3 \mathrm{ml}$ of chloroform:methanol (2:1), extracted twice with water, and centrifuged for 15 minutes at $3000 \mathrm{~g}$. For the triglyceride assay $200 \mu \mathrm{l}$ of the organic layer (lower phase) was removed and evaporated under $\mathrm{N}_{2}(g) .10 \mu \mathrm{l}$ of Thesit (Sigma-Aldrich, St Louis, MO) was added and mixed under $\mathrm{N}_{2}(g)$. Water $(50 \mu \mathrm{l})$ was added and incubated at $37^{\circ} \mathrm{C}$ for $1 \mathrm{hr}$ with intermittent vortexing. Aliquots of $5 \mu \mathrm{l}$ were assayed using the Serum Triglyceride Determination kit (Sigma-Aldrich, St Louis, MO) modified for a 96-well plate, calibrated with a trioleate (Sigma-Aldrich, St Louis, MO) standard curve. The cholesterol assay was performed at the same time but $500 \mu \mathrm{l}$ of the organic layer (lower phase) was removed after the centrifugation step and evaporated under $\mathrm{N}_{2}(g)$. $50 \mu \mathrm{l}$ of isopropanol was then added to the dried down lipids and mixed by vortexing. Aliquots of $2 \mu \mathrm{l}$ were then assayed using the Cholesterol E kit (Wako Chemicals USA, Richmond, USA).

\section{Statistical analyses}

Data processing and statistical analyses were performed using GraphPad Prism5. Student's $t$ test was applied to all sets of data for statistical comparisons between 
Table 1 The genes analyzed in this study and the sequences of the qPCR primer sets

\begin{tabular}{|c|c|c|c|}
\hline Gene & Official symbol & Product & Primers \\
\hline \multirow[t]{2}{*}{ Abcg5 } & Abcg5 & ATP-binding cassette, sub-family G (WHITE), member 5 & TGTCAACAGTATAGTGGCTCTG \\
\hline & & & CGTAAAACTCATTGACCACGAG \\
\hline \multirow[t]{2}{*}{ Abcg8 } & Abcg8 & ATP-binding cassette, sub-family G (WHITE), member 8 & CTTGTCCTCGCTATAGCAACC \\
\hline & & & TTTCCACAGAAAGTCATCAAAGC \\
\hline \multirow[t]{2}{*}{ Asbt } & Slc10a2 & Apical sodium-dependent bile acid transporter & ACСTTCCСАCTCATCTATACTG \\
\hline & & & CAAATGATGGCCTGGAGTCC \\
\hline \multirow[t]{2}{*}{ Bsep } & $A b c b 11$ & Bile salt export pump & CAACGCATTGCTATTGCTCGG \\
\hline & & & TAGACAAGCGATGAGCAATGAC \\
\hline \multirow[t]{2}{*}{ Cyp7a1 } & Cyp7a1 & Cholesterol 7 alpha hydroxylase & GGGAATGCCATTTACTTGGATC \\
\hline & & & TATAGGAACCATCCTCAAGGTG \\
\hline \multirow[t]{2}{*}{ Fabp6 } & Fabp6 & Fatty acid binding protein 6 & GAATTACGATGAGTTCATGAAGC \\
\hline & & & TTGCCAATGGTGAACTTGTTGC \\
\hline \multirow[t]{2}{*}{ Fgf15 } & Fgf15 & Fibroblast growth factor 15 & AGACGATTGCCATCAAGGACG \\
\hline & & & GTACTGGTTGTAGCCTAAACAG \\
\hline \multirow[t]{2}{*}{ FgfR4 } & Fgfr4 & Fibroblast growth factor receptor 4 & CTCGATCCGCTTTGGGAATTC \\
\hline & & & CAGGTCTGCCAAATCCTTGTC \\
\hline \multirow[t]{2}{*}{ FXR } & Nrih4 & Farnesoid $\mathrm{X}$ receptor (nuclear receptor subfamily 1 , group $\mathrm{H}$, member 4) & GTTCGGCGGAGATTTTCAATAAG \\
\hline & & & AGTCATTTGAGTTCTCCAACAC \\
\hline \multirow[t]{2}{*}{ BKlotho } & Klb & Beta Klotho & AACAGCTGTCTACACTGTGGG \\
\hline & & & ATGGAGTGCTGGCAGTTGATC \\
\hline \multirow[t]{2}{*}{ Mdr1a } & Abcbla & ATP-binding cassette, sub-family B member 1a & CCGATAAAAGAGCCATGTTTGC \\
\hline & & & CTTCTGCCTGATCTTGTGTATC \\
\hline \multirow[t]{2}{*}{ Mdr1b } & $A b c b 1 b$ & ATP-binding cassette sub-family B member $1 \mathrm{~b}$ & GGACCCAACAGTACTCTGATC \\
\hline & & & ACTTCTGCCTAATCTTGTGTATC \\
\hline \multirow[t]{2}{*}{ Mdr2 } & Abcb4 & Multidrug resistance protein 2 & TTGTCAATGCTAAATCCAGGAAG \\
\hline & & & AGTTCAGTGGTGCCCTTGATG \\
\hline \multirow[t]{2}{*}{ Mrp2 } & $A b c c 2$ & ATP-binding cassette, sub-family C (CFTR/MRP) member 2 & GGCTCATCTCAAATCCTITGTG \\
\hline & & & TTTGGATTTCGAAGCACGGC \\
\hline \multirow[t]{2}{*}{ Mrp3 } & Abcc3 & ATP-binding cassette, sub-family C (CFTR/MRP), member 3 & GAACACGTTCGTGAGCAGCC \\
\hline & & & ATCCGTCTCCAAGTCAATGGC \\
\hline \multirow[t]{2}{*}{ Mrp4 } & Abcc4 & ATP-binding cassette, sub-family C (CFTR/MRP), member 4 & TACAAGATGGTTCAGCAACTGG \\
\hline & & & GTCCATTGGAGGTGTTCATAAC \\
\hline \multirow[t]{2}{*}{ Ntcp } & Slc10a1 & Sodium-taurocholate co-transporting polypeptide & CGTCATGACACCACACTTACTG \\
\hline & & & GATGGTAGAACAGAGTTGGACG \\
\hline \multirow[t]{2}{*}{ Osta } & Osta & Organic solute transporter alpha & TCTCCATCTTGGCTAACAGTG \\
\hline & & & GATAGTACATTCGTGTCAGCAC \\
\hline \multirow[t]{2}{*}{ Ostb } & Ostb & Organic solute transporter beta & CCACAGTGCAGAGAAAGCTGC \\
\hline & & & ACATGCTTGTCATGACCACCAG \\
\hline \multirow[t]{2}{*}{ Shp } & NrOb2 & Small heterodimer partner & AGTCTITCTGGAGCCTTGAGC \\
\hline & & & TTGCAGGTGTGCGATGTGGC \\
\hline
\end{tabular}


Table 1 The genes analyzed in this study and the sequences of the qPCR primer sets (Continued)

\begin{tabular}{|c|c|c|c|}
\hline \multirow[t]{2}{*}{ Srbl } & Scarb1 & Scavenger receptor class B type 1 & GAACTGTTCTGTGAAGATGCAG \\
\hline & & & GCGTGTAGAACGTGCTCAGG \\
\hline \multirow[t]{2}{*}{ 36B4 } & Rplpo & Ribosomal protein, large, P0 & TCTGGAGGGTGTCCGCAAC \\
\hline & & & CTTGACCTTTCAGTAAGTGG \\
\hline
\end{tabular}

The top sequence of each set corresponds to the forward primer and the bottom one to the reverse. All reactions were done in $10 \mu$ final volume with 40 cycles of 30 seconds denaturing at $95^{\circ} \mathrm{C}, 30$ seconds annealing at $60^{\circ} \mathrm{C}$ and 30 seconds extension at $72^{\circ} \mathrm{C}$ (except annealing temperature for Ost $\beta$, which was $62^{\circ} \mathrm{C}$ ).

groups, the graphs show the means and the standard errors of the mean.

\section{Results}

\section{Enterohepatic infections downregulate the expression of intestinal Fgf15}

The terminal ileum is the main site of production of FGF15, it is also a major port of entry for Salmonella and therefore, an important site for its pathogenesis. To determine the effect of Salmonella infection on the homeostatic synthesis of FGF15, we collected tissue samples from infected animals and analyzed the abundance of Fgf15 transcripts by qPCR. As shown in Figures 1A and $1 \mathrm{~B}$, the level of Fgf15 transcripts inversely correlated with bacterial counts in the liver and the ileum, with a statistically significant decrease observed at mid-high infection levels. While H\&E-stained sections from the ileum of infected animals did not show signs of pathological alteration (Figure $1 \mathrm{C}$ ), staining of liver sections demonstrated a strong inflammatory response evidenced by large lesions with widespread lymphocytic infiltration, extensive necrosis often accompanied by local hemorrhage, and zones of parenchymal degeneration characterized by disappearance of hepatocytes (Figure 1D).

FGF15 is synthesized by enterocytes [6], which can also be invaded by Salmonella [23]. However, the decrease in Fgf15 expression was not associated with damage to the ileal enterocyte layer (Figure 1C). This suggests that loss of ileal enterocytes is not the reason for reduced Fgf15 transcript levels. Oral infections with Listeria monocytogenes, an inefficient invader of the mouse intestinal epithelium [24,25], showed no significant liver colonization and
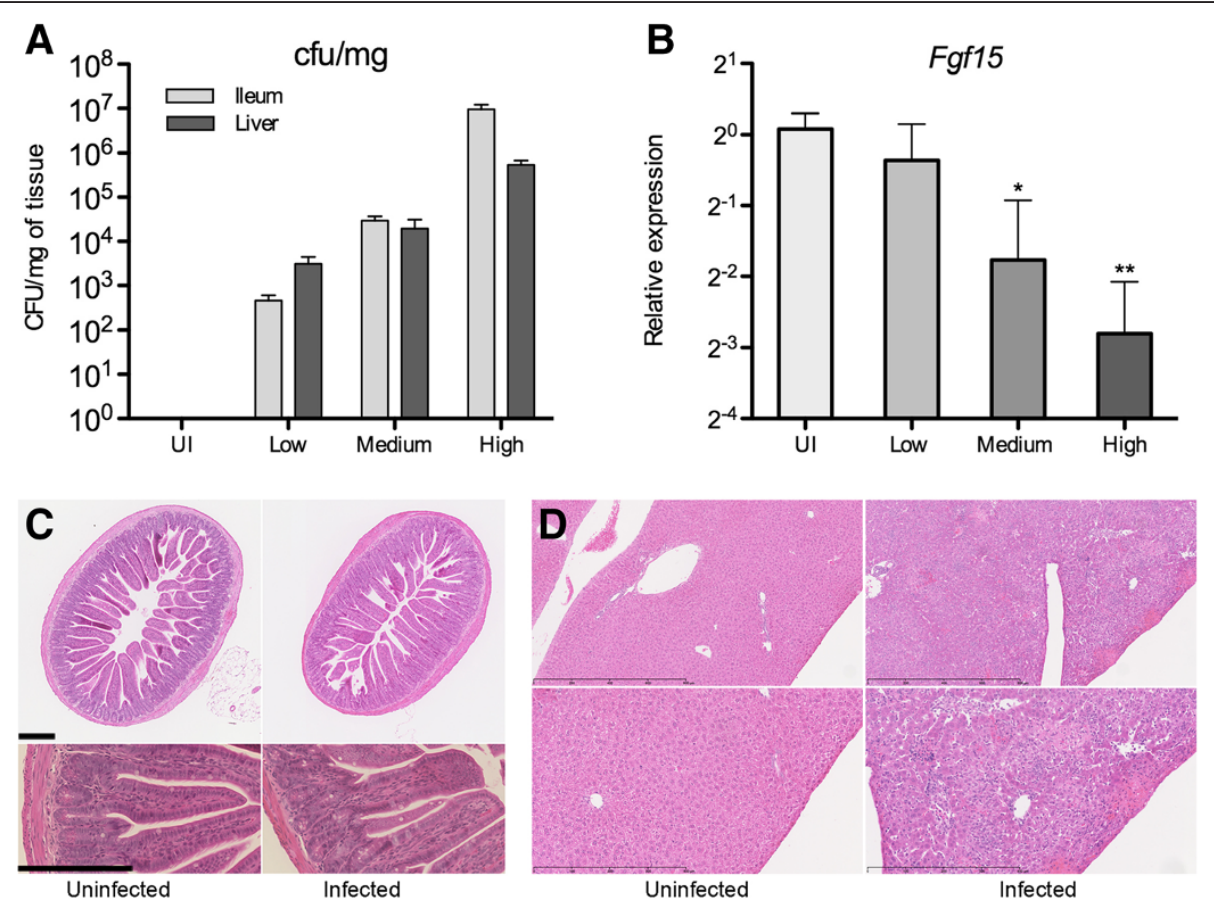

Figure 1 Oral infection with Salmonella typhimurium SL1344 decreases the expression of Fgf15 in the ileum. (A) bacterial counts in infected ilea and livers; animals were arbitrarily grouped into low, medium and high infection levels $\left(10^{0}-10^{3}, 10^{4}-10^{5}\right.$ and $>10^{6} \mathrm{cfu} / \mathrm{mg}$, respectively roughly corresponding to 72,96 and 120 hours post-infection; UI: uninfected). (B) relative levels of Fgf15 transcripts in the ilea of infected mice (data by qPCR). (C) H\&E staining of ileum sections from representative uninfected and orally Salmonella-infected animals (ileal colonization of the infected animal $=2.2 \times 10^{6} \mathrm{cfu} / \mathrm{mg}$ ); scale bars are $200 \mu \mathrm{m}$. (D) H\&E staining of liver sections from representative uninfected

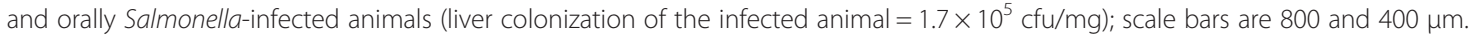


large numbers of intestinal bacteria but not downregulation of Fgf15 expression (Figure 2A). In contrast, intravenous infections with Listeria, which colonized the liver rapidly and triggered deccreases in the transcript levels of biliary function genes (Figure 2B), caused a significant reduction in ileal Fgf15 expression (Figure 2A). These results point to hepatic pathophysiology, rather than intestinal bacterial colonization, as the primary event driving downregulation of intestinal Fgf15 expression.

To establish the role of hepatic colonization and to probe the involvement of bacterial enterocyte invasion in repressing Fgf15 expression, we carried out intravenous infections with the Salmonella invasion-deficient strain SB103 following Menendez et al. [22]. In this type of infection, Salmonella colonization of the hepatobiliary system occurs immediately whereas colonization of the gut is delayed by 72 to 96 hours [22]. Furthermore, the bacteria that eventually reach the intestines are unable to invade the enterocytes due to the invA mutation of this strain. As shown in Figure 2C, intravenous infection with Salmonella SB103 caused a reduction of Fgf15 transcripts abundance. Notably, such a decrease was observed with a much lower intestinal bacterial burden than those in oral infections with the wild-type strain (average $10^{2} v s$. $10^{7} \mathrm{cfu} / \mathrm{mg}$, respectively). These results demonstrate that colonization of the hepatobiliary system by Salmonella represses the expression of intestinal Fgf15 and show that enterocyte invasion by intestinal bacteria does not play a major role on this effect.

Transcription of Fgf15 in ileal enterocytes is transactivated by the nuclear receptor FXR (Farnesoid X Receptor), upon its activation by bile acids [7]. Expression of the FXR gene (Nr1h4) was not affected by Salmonella, regardless of the intestinal bacterial burden (data not shown). In contrast, the expression of other known intestinal FXR target genes, Fabp6 (Fatty acid binding protein 6), NrOb2 (Small heterodimer partner, Shp) [26] and Osta (Organic solute transporter alpha) [27], was decreased by Salmonella infection in a pattern similar to that of Fgf15 with maximal, significant drops in highly-infected animals (Figure 3A). This suggests that activation of gene expression mediated by FXR is impaired during infection.

Colonization of the hepatobiliary system by Salmonella induces local pathological damage and inflammation [22],
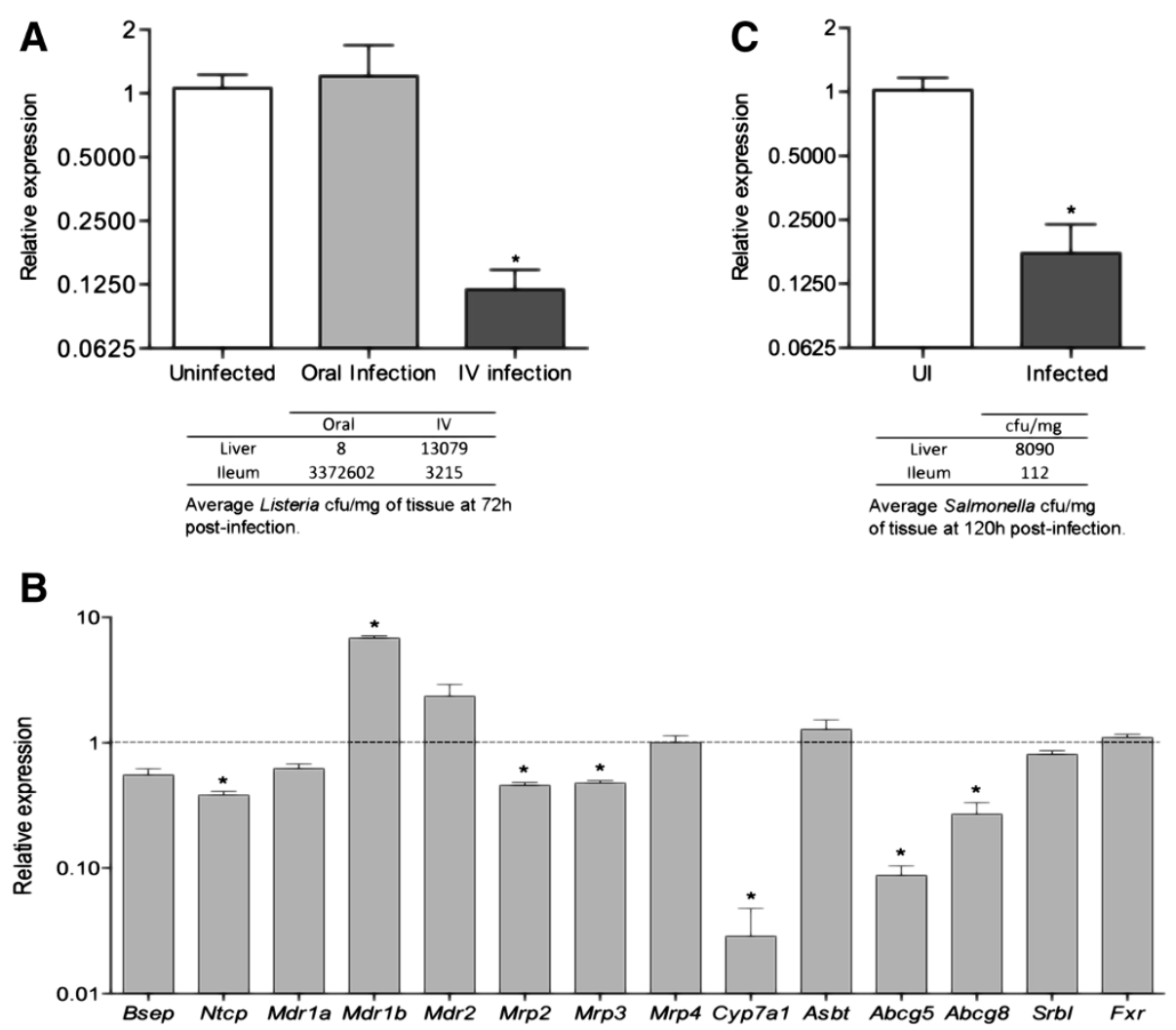

Figure 2 Liver colonization drives the downregulation of ileal Fgf15 expression. (A) relative levels of Fgf15 transcripts in the ileum of mice infected orally or intravenously with Listeria monocytogenes. (B) transcript levels of genes involved in liver biliary metabolism in mice infected intravenously with Listeria monocytogenes, relative to the levels of uninfected animals (defined as 1, dashed line). (C) relative levels of Fgf15 transcripts in the ilea of mice infected intravenously with Salmonella typhimurium SB103 (invA), at 120 hours post-infection. Data by $q P C R,{ }^{*} p<0.05$ 

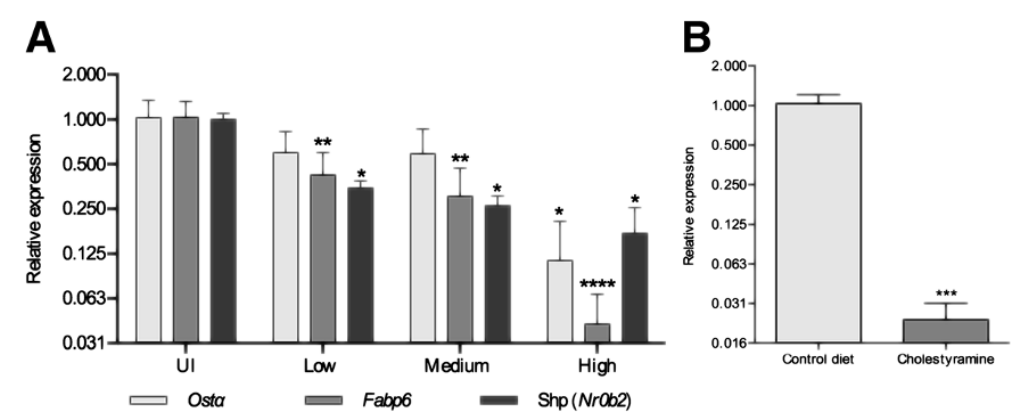

Figure 3 Infection with Salmonella decreases the expression of FXR-target genes in the ileum. (A) Relative levels of Fabp6, Nrob2 and Osta transcripts in the ileum of mice orally infected with Salmonella typhimurium SL1344. Animals were arbitrarily grouped into low, medium and high infection levels $\left(10^{0}-10^{3}, 10^{4}-10^{5}\right.$ and $>10^{6} \mathrm{cfu} / \mathrm{mg}$, respectively roughly corresponding to 72,96 and 120 hours post-infection; UI: uninfected). (B) Fgf15 transcript levels in the ilea of uninfected mice fed 5\% cholestyramine diet. Data by $\mathrm{qPCR},{ }^{* *} \mathrm{p}<0.01 ;{ }^{* * *} \mathrm{p}<0.001 ;{ }^{* * *} \mathrm{p}<0.0001$.

which can result in impaired synthesis of bile acids and inflammation-induced cholestasis [28]. This may in turn, compromise intestinal FXR activation and lead to inhibition of Fgf15, Fabp6, NrOb2 and Osta expression. To test whether the depletion of bile acids would be sufficient to decrease Fgf15 expression in vivo, we fed uninfected C57BL/6 mice with a diet supplemented with the bile acid sequestrant cholestyramine. As shown in Figure 3B mice fed with cholestyramine did have significantly lower levels of Fgf15 transcripts than mice fed with a normal diet.

Second, we evaluated the effects of Salmonella infection in bile production and flow. Gallbladder bile volumes were measured before and during infection; a significant reduction in volume was observed 24 hours post-infection, which did not improved over the next 4 days (Figure 4A). An expression analysis of hepatic genes involved in bile synthesis and secretion (Figure 4B), showed striking reductions in the transcript levels of the major transporters of bile acid and cholesterol (Abcb11, Slc10a1, Abcb1a, $A b c g 5$ and $A b c g 8)$ and the induction of several genes involved in rescue from cholestasis. The mRNA (Figure 5A) and protein levels (Figure 5B) of CYP7A1, the ratelimiting enzyme in the neutral pathway of bile acids synthesis, were decreased by infection. This was accompanied by a significant accumulation of hepatic cholesterol and triglycerides (Figure 5C and Figure 5D), which collectively suggest interruption of bile synthesis and flow.

\section{Salmonella infection leads to depletion of the hepatic FGF15 receptor complex}

Signaling of FGF15 in hepatocytes requires the tyrosine kinase membrane receptor FGFR4 and the protein
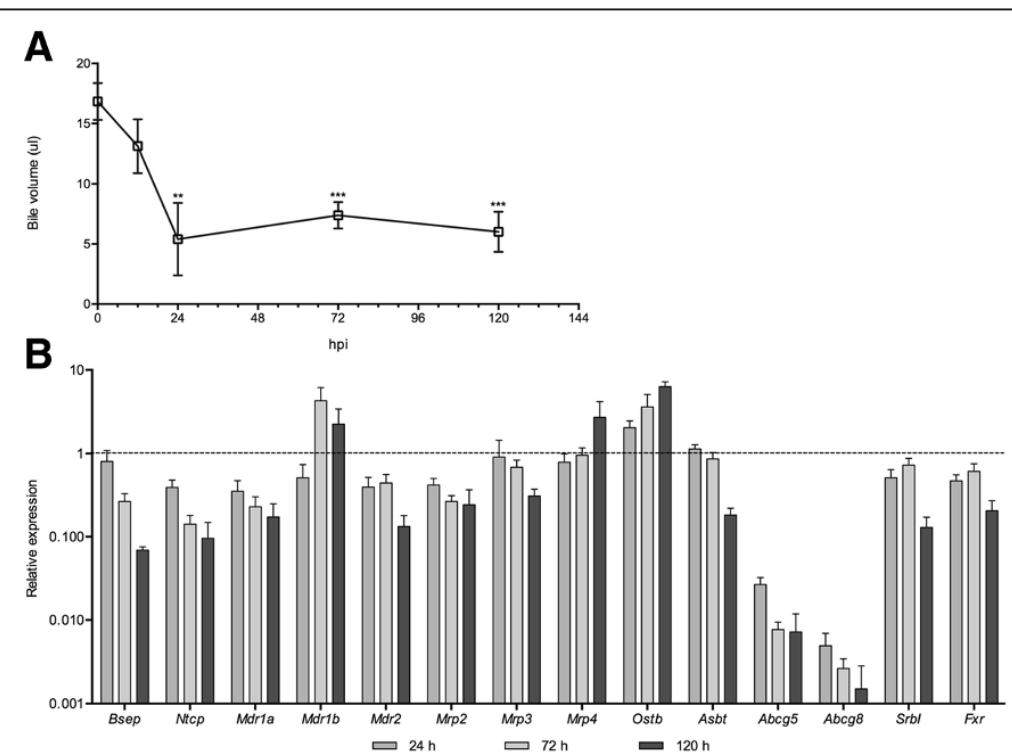

Figure 4 Salmonella infection perturbs the host's hepatobiliary homeostasis. (A) bile volumes recovered from the gallbladders of mice orally infected with Salmonella at the indicated hours post-infection (hpi). (B) Transcript levels of hepatic genes involved in liver biliary metabolism in mice infected with Salmonella, relative to the levels of uninfected animals (defined as 1, dashed line) at 24, 72 and 120 hours post-infection. Data by qPCR. 

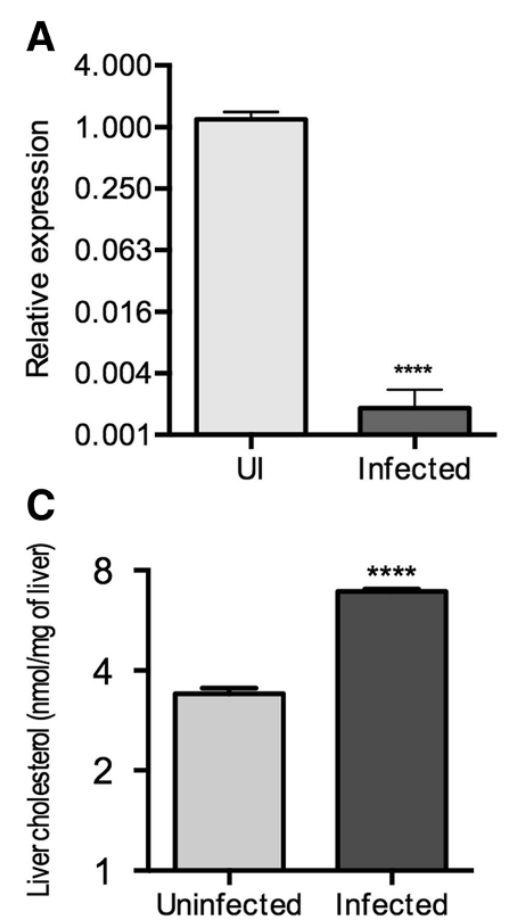

B
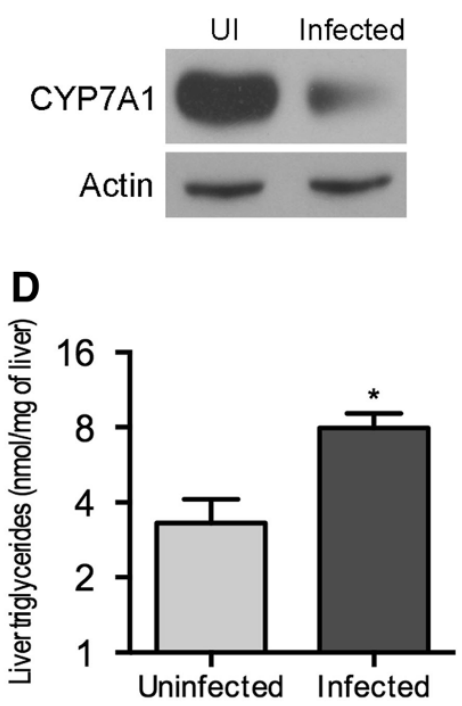

Figure 5 Salmonella infection downregulates the neutral bile acid synthesis pathway. (A) relative levels of liver Cyp7a1 transcripts in mice infected with Salmonella. (B) CYP7A1 western blot of liver lysates. (C) Cholesterol and (D) triglycerides accumulation in the liver of Salmonella-infected vs. uninfected mice, $\left({ }^{*} p<0.05 ;{ }^{* * * *} p<0.0001\right)$.

BKlotho. To determine if Salmonella infection disturbs the homeostasis of this pathway, we analyzed the levels of FGFR4 and BKlotho in infected and uninfected livers. Figures $6 \mathrm{~A}$ and $6 \mathrm{~B}$ show that the transcript levels of both Fgfr4 and Klb ( $\beta$ Klotho) were significantly decreased by infection. In addition, the protein levels were also reduced, as evidenced by western blot (Figure 6C). Two major FGFR4 bands were detected in uninfected animals, with apparent molecular weights of 115 and $125 \mathrm{KDa}$, likely corresponding to the core-glycosylated $\left(\right.$ FGFR $\left._{115}\right)$ and fully-glycosylated, functional (FGFR4 $4_{125}$ ) forms of FGFR4, respectively [29]. Infection led to the disappearance of FGFR $4_{125}$ and a decrease of FGFR $4_{115}$. Immunofluorescent staining of liver sections confirmed the reduction of FGFR4 and $\beta$ Klotho. Both proteins were clearly detected in uninfected hepatocytes (Figure 6D); in contrast, hepatocytes from Salmonella-infected livers were devoid of FGFR4 and $\beta$ Klotho.

\section{Discussion}

The FGF19-FGFR4 endocrine axis is currently considered a potential intervention point for the therapy of cancer, gallstone disease, and metabolic disorders associated to the metabolic syndrome [7,30]. Experimental administrations of FGF19 and transgenic FGF19 mice have shown decreased liver fat content, improved hepatic and serum lipid profiles, and resistance to high-fat diet-induced obesity [31-33]. In addition, FGF15/19 induces hepatocyte proliferation [34] and has been recently identified as an important mediator of liver regeneration after liver resection surgery [35]. Here we show that Salmonella infection disturbs the homeostasis of the FGF15/19-FGFR4 axis by down-regulating the expression of Fgf15, Fgfr4 and Klb. To our knowledge, these results constitute the first demonstration of a pathophysiological effect of bacterial infections over the FGF15/19-FGFR4 endocrine axis.

Infection modified both the ileal expression of $\mathrm{Fg} f 15$ and the components of its hepatic receptor, which suggests a significant functional shutdown of the pathway. Our data rules out a direct cytopathic effect of bacteria over ileal enterocytes as the major cause of Fgf15 mRNA reductions. Instead, it is apparent that the decline in Fgf15 expression results from impaired activation of FXR in the enterocytes. Our interpretation is strongly supported by the observed low volumes of gallbladder bile and the decreased expression of Fabp6, Osta and NrOb2 (Shp), all well-known FXR targets. In addition, we show that the depletion of the intestinal bile acids pool by oral administration of the bile acid sequestrant cholestyramine is sufficient to significantly decrease ileal Fgf 15 expression. Furthermore, intravenous infections with a Salmonella invasion mutant and with Listeria monocytogenes, both resulting in rapid hepatic colonization and pathophysiology, lead to reductions in 

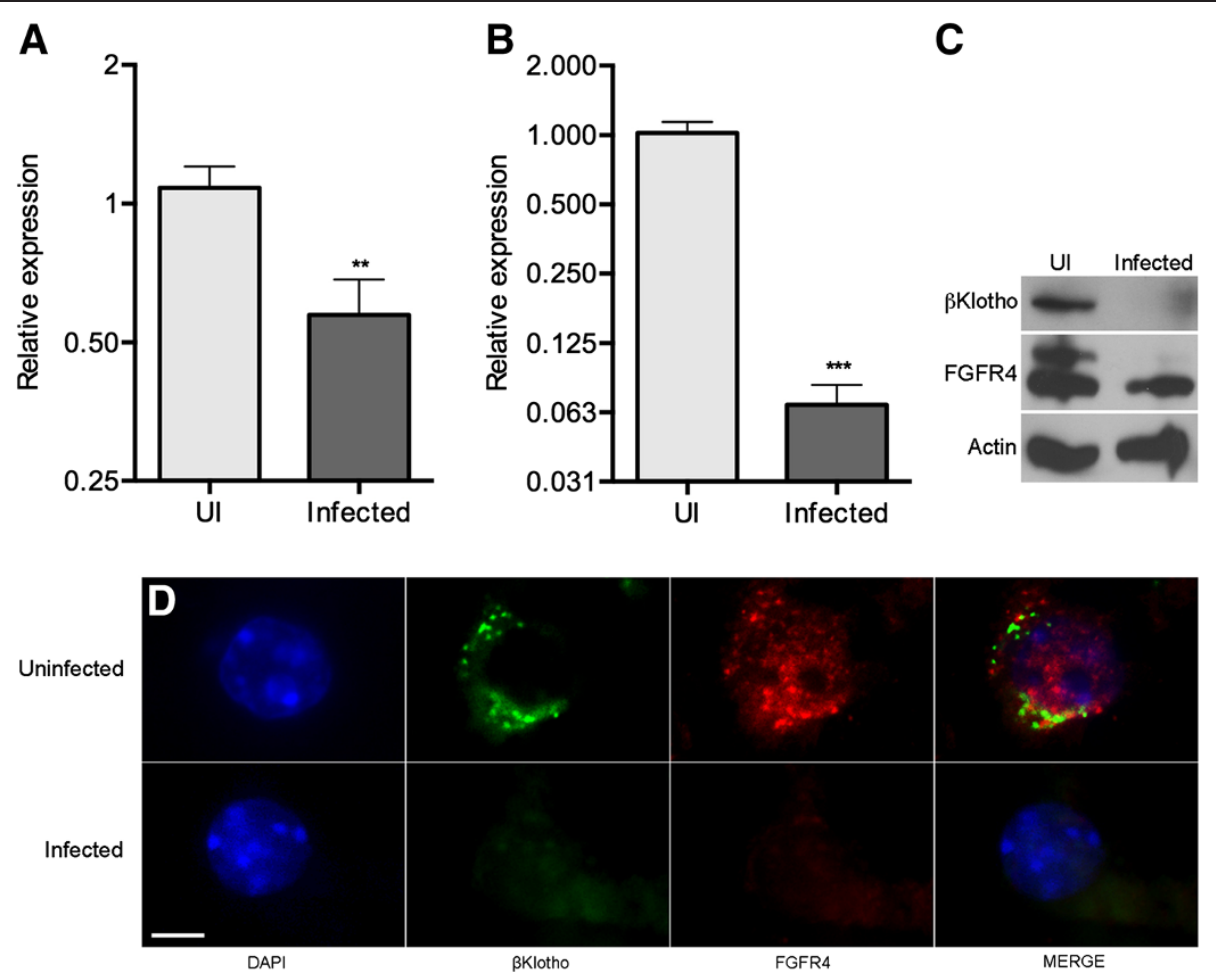

Figure 6 Salmonella infection causes the loss of the hepatic FGF15 receptor complex. (A) relative levels of Fgfr4 and (B) KIb (BKlotho) transcripts in the livers of mice infected with Salmonella. The animals analyzed in (A) and (B) are from the high-infection group in Figure 1, the data is by $q P C R,(* * p<0.01 ; * * * 00.001)$. (C) FGFR4 and $\beta$ KKlotho western blots of liver lysates. (D) FGFR4 and $\beta$ Klotho immunostaining of uninfected (top panel) and Salmonella-infected (bottom panel) liver samples. The figure shows a single, representative hepatocyte in each case. Scale bar is $5 \mu \mathrm{m}$.

Fgf15 expression in the absence of significant ileal bacterial colonization or enterocyte invasion.

Salmonella infection induced a massive alteration of the hepatobiliary gene expression program. Remarkably, the mRNA and protein levels of CYP7A1, the rate-limiting enzyme in the neutral pathway of bile acids synthesis were decreased during infection, in spite of the lower levels of FGF15 which would be expected to promote the upregulation of Cyp7a1 expression. These results reveal the complexities in the regulation of Cyp7a1 expression and indicates that the mechanisms of Cyp $7 a 1$ expression control are hierarchical. Infection also triggered a significant reduction of FGFR4 and $\beta$ Klotho, the two proteins involved in assembling the functional receptor for FGF15 in hepatocytes. The biology of FGFR4 and $\beta$ Klotho had never before been studied in the context of a bacterial insult, and our data suggest that their function can be severely compromised by bacterial infections in vivo. The mechanisms underlying their downregulation are unclear at present but we anticipate that they are related to the proinflammatory cytokine burst that follows liver colonization by bacteria. It has been recently reported that TNF $\alpha$ represses $\beta$ Klotho expression in adipocytes [36]; thus it is possible that a similar mechanism acts in hepatocytes.

It is apparent that the dysregulation of the FGF15/19FGFR4 endocrine axis components is not a general pathogenic feature of all bacteria, as infections with the enteric pathogen Citrobacter rodentium, the mouse model for human EPEC and EHEC [37], did not modify the expression of ileal Fgf15 (data not shown). Instead, this pathophysiological effect may be restricted to infections displaying a relevant liver involvement. Further work is still necessary to define the full impact of infections in FGF15/19 function and to determine the underlying molecular mechanisms.

\section{Conclusions}

Through the alteration of the hepatobiliary function, bacterial pathogens of the enterohepatic system dysregulate the homeostasis of the FGF15/19-FGFR4 endocrine axis. These revealing findings have important implications for the understanding of the pathophysiology of microbial diseases. Disruption of the FGF15/19-FGFR4 pathway may be a contributing factor to the metabolic 
and nutritional disorders associated with infectious diseases.

\section{Competing interests}

The authors declare that they have no competing interests.

\section{Authors' contributions}

GR, ST, ETA and LCMA carried out Salmonella infections. GR performed the gene expression analysis, western blots and immunofluorescent microscopy. SC and ETA performed the cholesterol and triglyceride determinations. MTC carried out the Listeria infections. BBF participated in the supervision of the study. GR and AM drafted the manuscript. AM conceived the study and supervised its design, coordination and execution. All authors read and approved the final manuscript.

\section{Acknowledgments}

We thank Catherine Desrosiers, Melisange Roux and Elora Midavaine for technical help. This work was supported by grants to A.M. from the Fonds de Recherche du Québec-Santé (26710) and the Natural Sciences and Engineering Research Council of Canada (401949-2011), and to B.B.F. from the Canadian Institutes for Health Research. L. C. M. A. was funded by a postdoctoral fellowship from the Canadian Institutes of Health Research. A. M. is a member of the FRQS-funded Centre de Recherche Clinique Étienne-Le Bel.

\section{Author details}

'Department of Microbiology and Infectious Diseases, Faculty of Medicine and Health Sciences, University of Sherbrooke, Cancer Research Pavilion, Rm Z8-1072, 3201, rue Jean-Mignault, Sherbrooke, Québec J1E 4K8, Canada. ${ }^{2}$ Michael Smith Laboratories, The University of British Columbia, Vancouver, BC V6T 1Z4, Canada. ${ }^{3}$ Department of Biochemistry and Molecular Biology, The University of British Columbia, Vancouver, BC V6T 1Z3, Canada. ${ }^{4}$ Department of Microbiology and Immunology, University of British Columbia, Vancouver, BC V6T 1Z3, Canada. ${ }^{5}$ Present address: Unité de Pathogénie Microbienne Moléculaire Institut Pasteur, 28 rue du Dr Roux F - 75724, Paris Cédex 15, France. ${ }^{6}$ Present address: Escola Nacional de Saúde Pública Sergio Arouca, Fundação Oswaldo Cruz, Rua Leopoldo Bulhões, 1480, Rio de Janeiro, RJ 21041-210, Brazil. "Present address: Qu Biologics Inc, 887 Great Northern Way, Suite 138, Vancouver, BC V5T 4T5, Canada.

Received: 18 June 2013 Accepted: 26 October 2013

Published: 29 October 2013

\section{References}

1. Powanda MC, Beisel WR: Metabolic effects of infection on protein and energy status. J Nutr 2003, 133(1):322S-327S.

2. McGuinness OP: Defective glucose homeostasis during infection. Annu Rev Nutr 2005, 25:9-35.

3. Khosla SN: Typhoyd fever. Its cause, transmission and prevention. New Delhi: Atlantic Publishers; 2008.

4. Antunes LC, Arena ET, Menendez A, Han J, Ferreira RB, Buckner MM, Lolic P, Madilao LL, Bohlmann J, Borchers CH, et al: Impact of salmonella infection on host hormone metabolism revealed by metabolomics. Infect Immun 2011, 79(4):1759-1769.

5. Parry CM: Epidemiological and clinical aspects of human typhoid fever. In Salmonella infections: clinical, immunological and molecular aspects. Edited by Mastroeni P, Maskell D. Cambridge, New York: Cambridge University Press; 2006.

6. Inagaki T, Choi M, Moschetta A, Peng L, Cummins CL, McDonald JG, Luo G, Jones SA, Goodwin B, Richardson JA, et al: Fibroblast growth factor 15 functions as an enterohepatic signal to regulate bile acid homeostasis. Cell Metab 2005, 2(4):217-225

7. Jones SA: Physiology of FGF15/19. In Endocrine FGFs and Klothos. Edited by Kuro-o M. New York: Landes Bioscience and Springer Science; 2012:171-182.

8. Potthoff MJ, Kliewer SA, Mangelsdorf DJ: Endocrine fibroblast growth factors 15/19 and 21: from feast to famine. Genes Dev 2012, 26(4):312-324.

9. Chiang JY: Bile acids: regulation of synthesis. J Lipid Res 2009, 50(10):1955-1966
10. Sinha J, Chen F, Miloh T, Burns RC, Yu Z, Shneider BL: Beta-Klotho and FGF-15/19 inhibit the apical sodium-dependent bile acid transporter in enterocytes and cholangiocytes. Am J Physiol Gastrointest Liver Physiol 2008, 295(5):G996-G1003.

11. Choi M, Moschetta A, Bookout AL, Peng L, Umetani M, Holmstrom SR, Suino-Powell K, Xu HE, Richardson JA, Gerard RD, et al: Identification of a hormonal basis for gallbladder filling. Nat Med 2006, 12(11):1253-1255.

12. Yu C, Wang F, Kan M, Jin C, Jones RB, Weinstein M, Deng CX, McKeehan WL: Elevated cholesterol metabolism and bile acid synthesis in mice lacking membrane tyrosine kinase receptor FGFR4. J Biol Chem 2000, 275(20):15482-15489.

13. Ito S, Fujimori T, Furuya A, Satoh J, Nabeshima Y: Impaired negative feedback suppression of bile acid synthesis in mice lacking betaKlotho. J Clin Invest 2005, 115(8):2202-2208.

14. Kuro-o M: Klotho and betaKlotho. Adv Exp Med Biol 2012, 728:25-40.

15. Lenicek M, Duricova D, Komarek V, Gabrysova B, Lukas M, Smerhovsky Z, Vitek L: Bile acid malabsorption in inflammatory bowel disease: assessment by serum markers. Inflamm Bowel Dis 2011, 17(6):1322-1327.

16. Walters JR, Tasleem AM, Omer OS, Brydon WG, Dew T, le Roux CW: A new mechanism for bile acid diarrhea: defective feedback inhibition of bile acid biosynthesis. Clin Gastroenterol Hepatol 2009, 7(11):1189-1194.

17. Schaap FG, van der Gaag NA, Gouma DJ, Jansen PL: High expression of the bile salt-homeostatic hormone fibroblast growth factor 19 in the liver of patients with extrahepatic cholestasis. Hepatology 2009, 49(4):1228-1235.

18. Schreuder TC, Marsman HA, Lenicek M, van Werven JR, Nederveen AJ, Jansen PL, Schaap FG: The hepatic response to FGF19 is impaired in patients with nonalcoholic fatty liver disease and insulin resistance. Am J Physiol Gastrointest Liver Physiol 2010, 298(3):G440-G445.

19. Galan JE, Curtiss R 3rd: Distribution of the invA, $-B,-C$, and $-D$ genes of Salmonella typhimurium among other Salmonella serovars: invA mutants of Salmonella typhi are deficient for entry into mammalian cells. Infect Immun 1991, 59(9):2901-2908.

20. Bishop DK, Hinrichs DJ: Adoptive transfer of immunity to Listeria monocytogenes. The influence of in vitro stimulation on lymphocyte subset requirements. J Immunol 1987, 139(6):2005-2009.

21. Pfaffl MW: A new mathematical model for relative quantification in real-time RT-PCR. Nucleic Acids Res 2001, 29(9):e45.

22. Menendez A, Arena ET, Guttman JA, Thorson L, Vallance BA, Vogl W, Finlay BB: Salmonella infection of gallbladder epithelial cells drives local inflammation and injury in a model of acute typhoid fever. J Infect Dis 2009, 200(11):1703-1713.

23. van Asten AJ, Koninkx JF, van Dijk JE: Salmonella entry: M cells versus absorptive enterocytes. Vet Microbiol 2005, 108(1-2):149-152.

24. Okamoto M, Nakane A, Minagawa T: Host resistance to an intragastric infection with Listeria monocytogenes in mice depends on cellular immunity and intestinal bacterial flora. Infection and immunity 1994, 62(8):3080-3085.

25. Lecuit M: Understanding how Listeria monocytogenes targets and crosses host barriers. Clin Microbiol Infect 2005, 11(6):430-436.

26. De Gottardi A, Touri F, Maurer CA, Perez A, Maurhofer O, Ventre G, Bentzen $\mathrm{CL}$, Niesor EJ, Dufour JF: The bile acid nuclear receptor FXR and the bile acid binding protein IBABP are differently expressed in colon cancer. Dig Dis Sci 2004, 49(6):982-989.

27. Frankenberg T, Rao A, Chen F, Haywood J, Shneider BL, Dawson PA: Regulation of the mouse organic solute transporter alpha-beta, Ostalpha-Ostbeta, by bile acids. Am J Physiol Gastrointest Liver Physiol 2006, 290(5):G912-G922.

28. Kosters A, Karpen $\mathrm{S}$ : The role of inflammation in cholestasis: clinical and basic aspects. Semin Liver Dis 2010, 30(2):186-194.

29. Triantis V, Saeland E, Bijl N, Oude-Elferink RP, Jansen PL: Glycosylation of fibroblast growth factor receptor 4 is a key regulator of fibroblast growth factor 19-mediated down-regulation of cytochrome P450 7A1. Hepatology 2010, 52(2):656-666.

30. Wu X, Li Y: Therapeutic utilities of fibroblast growth factor 19. Expert Opin Ther Targets 2011, 15(11):1307-1316.

31. Tomlinson E, Fu L, John L, Hultgren B, Huang X, Renz M, Stephan JP, Tsai SP, Powell-Braxton L, French D, et al: Transgenic mice expressing human fibroblast growth factor-19 display increased metabolic rate and decreased adiposity. Endocrinology 2002, 143(5):1741-1747.

32. Fu L, John LM, Adams SH, Yu XX, Tomlinson E, Renz M, Williams PM, Soriano R, Corpuz R, Moffat B, et al: Fibroblast growth factor 19 increases 
metabolic rate and reverses dietary and leptin-deficient diabetes. Endocrinology 2004, 145(6):2594-2603.

33. Bhatnagar S, Damron HA, Hillgartner FB: Fibroblast growth factor-19, a novel factor that inhibits hepatic fatty acid synthesis. J Biol Chem 2009, 284(15):10023-10033.

34. Wu X, Ge H, Lemon B, Vonderfecht S, Weiszmann J, Hecht R, Gupte J, Hager T, Wang Z, Lindberg R, et al: FGF19-induced hepatocyte proliferation is mediated through FGFR4 activation. J Biol Chem 2010, 285(8):5165-5170.

35. Uriarte I, Fernandez-Barrena MG, Monte MJ, Latasa MU, Chang HC, Carotti S, Vespasiani-Gentilucci U, Morini S, Vicente E, Concepcion AR, et al: Identification of fibroblast growth factor 15 as a novel mediator of liver regeneration and its application in the prevention of post-resection liver failure in mice. Gut 2013, 62(6):899-910.

36. Diaz-Delfin J, Hondares E, Iglesias R, Giralt M, Caelles C, Villarroya F: TNF-alpha represses beta-Klotho expression and impairs FGF21 action in adipose cells: involvement of JNK1 in the FGF21 pathway. Endocrinology 2012, 153(9):4238-4245.

37. Diez E, Zhu L, Teatero SA, Paquet M, Roy MF, Loredo-Osti JC, Malo D, Gruenheid S: Identification and characterization of Cri1, a locus controlling mortality during Citrobacter rodentium infection in mice. Genes Immun 2011, 12:280-290

doi:10.1186/1471-2180-13-238

Cite this article as: Romain et al:: Enterohepatic bacterial infections dysregulate the FGF15-FGFR4 endocrine axis. BMC Microbiology 2013 13:238.

\section{Submit your next manuscript to BioMed Central and take full advantage of:}

- Convenient online submission

- Thorough peer review

- No space constraints or color figure charges

- Immediate publication on acceptance

- Inclusion in PubMed, CAS, Scopus and Google Scholar

- Research which is freely available for redistribution 